\title{
EXPERIMENTS INVESTIGATING THE GENERATION AND TRANSPORT OF 10-12 MeV, 30-kA, mm-SIZE ELECTRON BEAMS WITH LINEAR INDUCTIVE VOLTAGE ADDERS SAND--97-0139C
}

M. G. Mazarakis, J. W. Poukey, J. E. Maenchen, D. C. Rovang, P. R. Menge, J. S. Lash, D. L.

Smith, J. A. Halbleib, S. R. Cordova, K. Mikkelson, J. Gustwiller, and W. A. Stygar

Sandia National Laboratories, P.O. Box 5800, Albuquerque, NM 87185-1193

D. R. Welch, Mission Research Corporation, Albuquerque, NM 87106

I. Smith and P. Corcoran, Pulse Sciences Incorporated, San Leandro, CA 94577

Abstract

We present the design, analysis, and results of the highbrightness electron beam experiments currently under investigation at Sandia National Laboratories. The anticipated beam parameters are the following: $8-12 \mathrm{MeV}$, 35-50 kA, 30-60 ns FWHM, and 0.5-mm rms beam radius. The accelerators utilized are SABRE and HERMES III. Both are linear inductive voltage adders modified to higher impedance and fitted with magnetically immersed foilless electron diodes. In the strong 20-50 Tesla solenoidal magnetic field of the diode, mm-size electron beams are generated and propagated to a beam stop. The electron beam is field emitted from mmdiameter needle-shaped cathode electrode and is contained in a similar size envelope by the strong magnetic field. These extremely space charge dominated beams provide the opportunity to study beam dynamics and possible instabilities in a unique parameter space. The SABRE experiments are already completed and have produced 30 $\mathrm{kA}, 1.5-\mathrm{mm}$ FWHM electron beams, while the HERMES-III experiments are on-going.

\section{INTRODUCTION}

The experiments reported here were motivated by the success of converting RADLAC II (an induction linac) into an equal impedance $(-120 \mathrm{ohm})$ inductive voltage adder coupled to a magnetically immersed foilless diode (RADLAC II/SMILE) [1]. The inductive voltage adder (IVA) technology is relatively simple and couples a selfmagnetically insulated transmission line (MITL) [2] with an induction linac to generate a new family of induction accelerators. In these accelerators, the particle beam which drifts through the multiple cavities of conventional induction linacs is replaced by a metal conductor which extends along the entire length of the device. The voltage addition of the accelerating cavities is therefore accumulated in the TEM Poynting vector rather than in a sequentially accelerated electron beam.

In the next sections, we present results and analysis of the SABRE [3] experiments and a progress report on HERMES-III [4] experiments.

\section{astraur RAST TER}

\section{SABRE EXPERIMENTS}

SABRE has 10 inductively insulated cavities, each rated at $1 \mathrm{MV}$, designed to operate at $40 \mathrm{ohms}$ in negative polarity and $20 \mathrm{ohms}$ in positive polarity. For these experiments, SABRE was modified to increase the output voltage and proportionally reduce the current, delivering the same energy. It was, therefore, operated at 9-12 MV and 100$120 \mathrm{kA}$. The major accelerator modifications reduced the total number of pulse forming lines by half and utilized a new cathode electrode. Thus, each cavity was fed by a single pulse forming line, doubling the accelerator impedance which was further increased to $120 \mathrm{ohms}$ by the new smaller diameter cathode electrode $[5,6,7]$.

The MITL voltage adder and foilless diode (Fig. 1) were designed using particle-in-cell simulations. Because of the large range in space and time scales, the entire design was divided into three parts: the voltage adder, the transition region, where the coupling from the MITL into the immersed diode was studied; and finally, the immersed diode where the beam generation and beam parameters were analyzed in fine detail (Fig. 2). The diode simulations represent an ideal situation assuming no ion emission from the target, perfect cylindrical symmetry and no instabilities between counterstreaming electrons and ions.

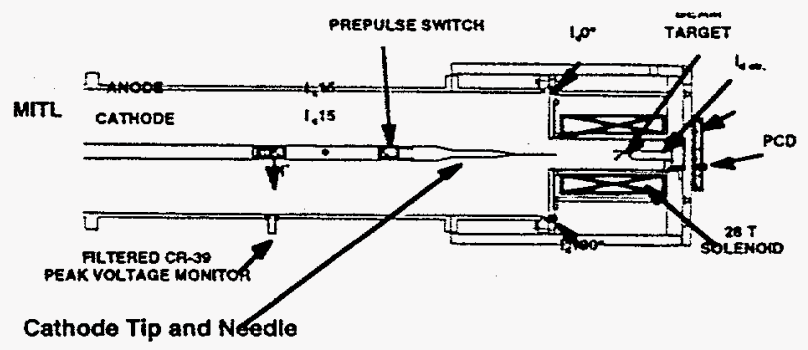

Figure 1. Schematic diagram of diode design and transition region, showing details and B-dot monitors. 


\section{DISCLAIMER}

This report was prepared as an account of work sponsored by an agency of the United States Government. Neither the United States Government nor any agency thereof, nor any of their employees, make any warranty, express or implied, or assumes any legal liability or responsibility for the accuracy, completeness, or usefulness of any information, apparatus, product, or process disclosed, or represents that its use would not infringe privately owned rights. Reference herein to any specific commercial product, process, or service by trade name, trademark, manufacturer, or otherwise does not necessarily constitute or imply its endorsement, recommendation, or favoring by the United States Government or any agency thereof. The views and opinions of authors expressed herein do not necessarily state or reflect those of the United States Government or any agency thereof. 


\section{DISCLAIMER}

\section{Portions of this document may be illegible}

in electronic image products. Images are produced from the best available original document. 


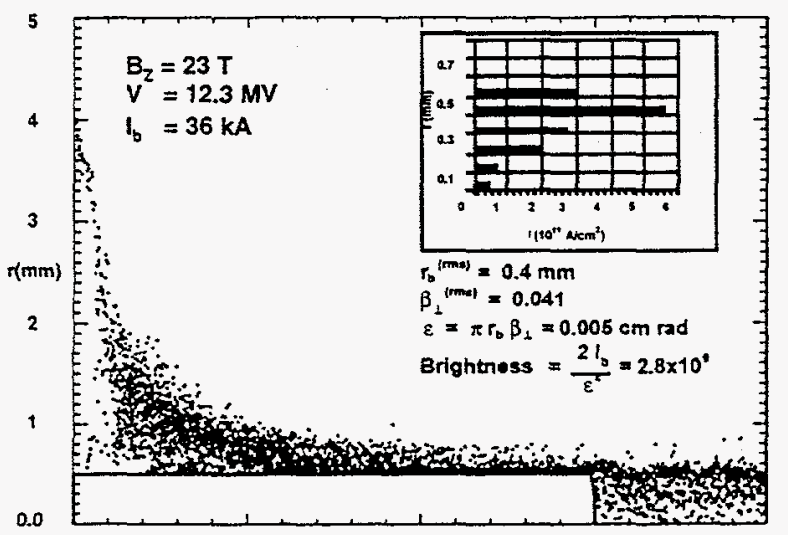

Figure 2. High-resolution diode simulation calculating the beam parameters.

The intense electron beam produced by the SABRE foilless diode quickly produces an ion-emitting anode plasma. The ions, mostly protons, are accelerated toward the cathode with a current reduced roughly by the ratio of the ion-to-electron beam velocity ( $3 \mathrm{kA}$ ions versus $30 \mathrm{kA}$ electrons for typical SABRE parameters). The electrostatic attraction between the two beams is considerable and various forms of the two-stream instability can be excited, including sausage, hollowing, hose, and filamentation. These instabilities can cause large deflections and heating of the beam which would increase the beam spot size in the absence of a strong axial magnetic field $\left(B_{Z}\right)$. According to theory and IVORY simulations, a $30-\mathrm{T}$ or higher field controls these instabilities and allows 0.5 to $0.75 \mathrm{~mm}$ radius beams. The experimental results are in very good agreement with IVORY simulations [8] (Table I). Figure 3 presents two time-integrated pinhole $x$-ray images of the beam on the anode target for two magnetic field strengths: $6 \mathrm{~T}$ (Fig. 3a) and $28.5 \mathrm{~T}$ (Fig. 3b).

Table 1

\begin{tabular}{|c|c|c|}
\hline & \multicolumn{2}{|c|}{ Beam Spot FWHM (mm) } \\
\hline $\mathrm{B}_{7}(\mathrm{~T})$ & Experiment & TVORY Simulation \\
\hline 6 & 3.1 & 2.83 \\
\hline 29 & 1.5 & 1.25 \\
\hline
\end{tabular}

SABRE experiments demonstrated that a magnetically immersed foilless diode driven by an inductive voltage adder can produce $1.5 \mathrm{~mm}$ (FWHM) electron beams. $A-30 \mathrm{~T}$ solenoidal magnetic field controlled the ion hose instability and prevented beam disnuption. The experimentally measured voltage, current, $x$-ray dose, $\beta_{1}$, and spot size are in excellent agreement with analytical theory and numerical simulations.

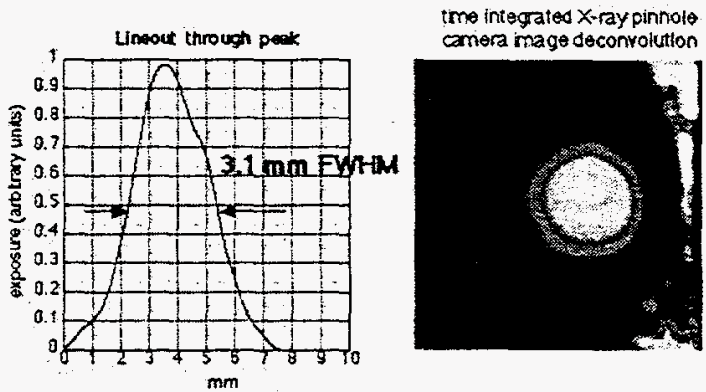

Figure 3a. Time-integrated $x$-ray images of the beam for $B_{Z}=6 \mathrm{~T}$.
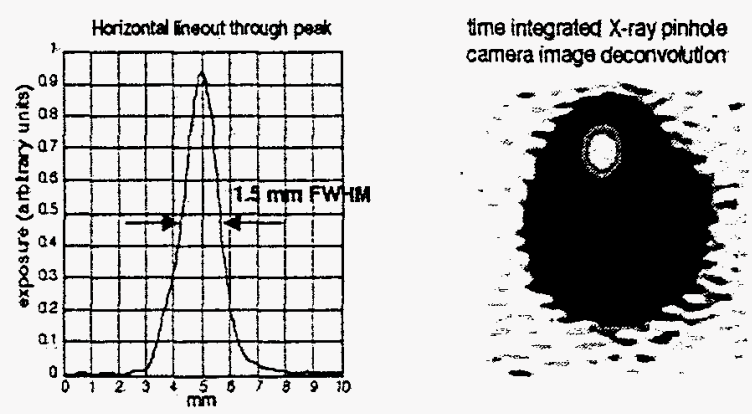

Figure $3 b$. Time-integrated $x$-ray images of the beam for $\mathrm{B}_{\mathrm{Z}}=29 \mathrm{~T}$.

\section{HERMES-III EXPERIMENTS}

We currently utilize the HERMES-III accelerator to extend SABRE results to higher voltage (12 MV), longer pulse length ( $\sim 70$ ns FWHM), and higher diode magnetic field $(50 \mathrm{~T})$. The higher magnetic field should produce even smaller beam spot sizes of the order of $0.75 \mathrm{~mm}$ FWHM. The increased voltage and pulse length are required to achieve $1 \mathrm{kRad} x$-ray dose at $1 \mathrm{~m}$ from the $\mathrm{Ta}$ target.

HERMES III is larger than SABRE, having 20 inductively insulated cavities, each rated to a 1-MV maximum voltage. A number of modifications converted HERMES from routine parameters ( $18 \mathrm{MV}, 700 \mathrm{kA}, 20$ $\mathrm{ns})$ to our levels $(12 \mathrm{MV}, 150 \mathrm{kA}, 70 \mathrm{~ns})$ : the pulse forming line length was doubled, a new cathode electrode increased the final impedance to $110 \mathrm{ohms}$, and the Marx generators were charged to lower voltage $(60 \mathrm{kV})$. The cantilevered cathode electrode is now of much smaller radius and longer $(18 \mathrm{~m})$. To increase its strength continuous tapered sections were utilized instead of the stairstep design approach of previous voltage adders $[5,6]$. The outer cylinder of the extension MITL also has conical sections to reduce the radius down to SABRE size. Thus, the same magnetically immersed diode (Fig. 1) assemblies are utilized with HERMES III. In addition, a smaller, 50Tesla, cryogenic diode was designed and constructed. 
HERMES III is a very reliable accelerator and performed as expected. We produced with great reproducibility $12 \mathrm{MV}, 150 \mathrm{kA}, 70 \mathrm{~ns}$ FWHM pulses with 50 ns flat top at the output end of the long extension MITL.

During SABRE experimentation we observed a severe decrease in the diode impedance near the peak of the voltage pulse. It was attributed to a combination of a $100-\mathrm{kV}$ prepulse arriving 200 ns before the main pulse and poor vacuum ( $1 \times 10^{-5}$ torr). A flashover prepulse suppression switch and improved pumping $\left(<2 \times 10^{-6}\right.$ torr) solved the problem. The modified HERMES III produces a similar amplitude prepulse, and similar prepulse flashover switches were installed on the cathode electrode $30 \mathrm{~cm}$ upstream from the AK gap. Unfortunately, because of unexpected air and oil leaks inside the accelerator column, we are as yet unable to take advantage of the available long pulse and make the diode operate at constant impedance for the entire 70 ns. Fig. 4 shows voltage, diode current and diode impedance for SABRE normal operation (Fig. 4a) with prepulse flashover switch in place and good vacuum. Fig. $4 b$ presents similar HERMES III diode parameters with the present poor vacuum $\left(7 \times 10^{-6}\right.$ torr) and oil contaminated system. At the beginning of the pulse, the impedance appears reasonable, and the first few frames of the $x$-ray framing camera [6] show beam spot sizes similar to SABRE and in good agreement with the simulations. However, the diode impedance quickly collapses and the beam disappears. Opening the AK gap to $20 \mathrm{~cm}$ seems to help the diode operation and substantially delay the impedance decay.

We are in the process of identifying and fixing the accelerator air leaks. To solve the oil leak problem, a number of accelerating cavities will be replaced, diffusion pumps will be installed in the accelerator, and sections of the extension MITL will be provided with cryowalls.

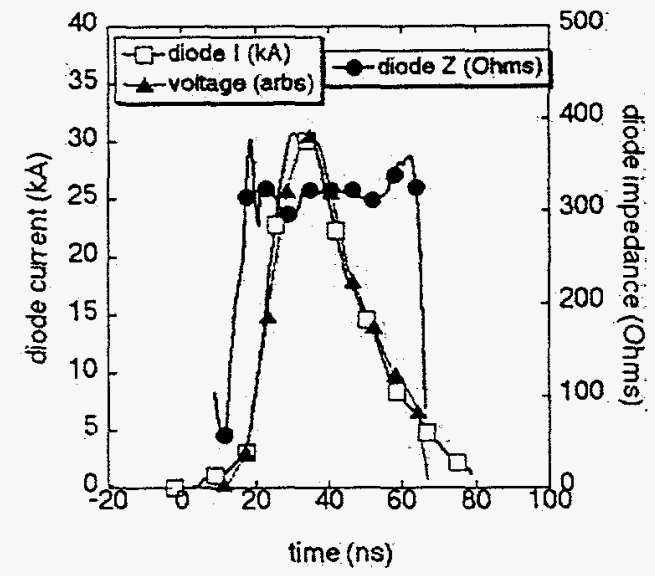

Figure 4a. A constant impedance diode shot with SABRE.

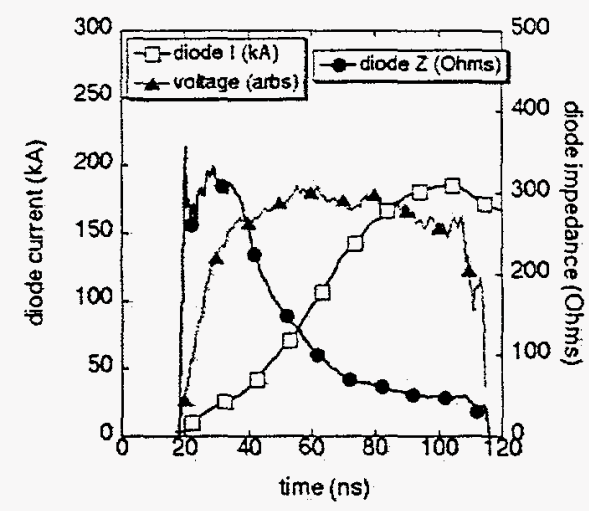

Figure $4 \mathrm{~b}$. The impedance of the HERMES-III diode decays with time, probably due to poor accelerator vacuum and oil contamination.

\section{CONCLUSIONS}

We have designed, constructed, and experimentally tested immersed diodes and high-impedance voltage adders for SABRE and HERMES III, which should generate very intense high-brightness electron beams of millimeter size. In our first experimental validation of the design with SABRE, ion-hose instabilities have imposed a lower spot size limit of $1.5-\mathrm{mm}$ FWHM to the beam. The $50-\mathrm{T}$ HERMES-III experiments should further minimize the ion-hose effect and reduce the beam spot size to $\sim 0.7 \mathrm{~mm}$ FWHM. Unfortunately, in our first experimental campaign, poor accelerator vacuum and oil leaks prevented us from reaching our goals which we hope to achieve in the very near future.

\section{ACKNOWLEDGMENTS}

Sandia is a multiprogram laboratory operated by Sandia Corporation, a Lockheed Martin Company, for the U.S. DOE under Contract DE-ACO4-94AL85000.

\section{REFERENCES}

[1] M. G. Mazarakis, J. W. Poukey, S. L. Shope, C. A. Frost, B. N Turman, J. J. Ramirez, and K. R. Prestwich, Proc. 8th Int. IEEE Pulsed Power Conf., (San Diego, CA. 1991), p. 86.

[2] J. M. Creedon, J. Appl. Phys, 48 (3) 1070 (1977)

[3] J. Corley, J. A. Alexander, P. J. Pankuch, C. E. Heath, D. L. Johnson, J. J. Ramirez, and G. J. Denison, Proc. 8th Int. IEEE Pulsed Power Conf., (San Diego, CA, 1991), p. 920.

[4] J. J. Ramirez, K. R. Prestiwch, E. L. Burgess, J. P. Furaus, R A Hamil, D. L. Johnson, T. W. L. Sanford, L. E. Seamons, L. X. Schneider, and G. A. Zawadzkas, Proc. Gith Int. IEEE Pulsed Power Conf., (Arlington, VA, 1987), p. 294.

[5] M. G. Mazarakis, J. W. Poukey, D. Rovang, S. Cordova, P. Pankuch, R. Wavrik, D. L. Smith, J. E. Maenchen, L. Bennett, K. Shimp, and K. Law, in Space Charge Dominated Beams and Applications of High Brightness Beams, edited by S. Y. Lee, (AIP, New York. 1996), p. 479.

[6] M. G. Mazarakis, J. W. Poukey, D. C. Rovang, J. E. Maenchen, S. R. Cordova, P. R. Menge, R. Pepping, K. Mikkelson, D. L. Srmith, I. Halbleib, and W. A. Stygar, Appl. Phys. Lett. 70 (7), 832 (1997).

[7] M. G. Mazarakis, J. W. Poukey, C. A. Frost, D. L. Johnson, S. L. Shope, J. A. Halbleib, K. R. Prestwich, B. N. Turman, and I. Smith, Proc. IEEE Int. Conf. on Plasma Science, (Tampa, FL, 1992), p. 104.

[8] D. R. Welch, M. A. Mostrom, and R. E. Clark, Mission Research Corporation internal report MRC/ABQ-R-1766 (1995); MRC/ABQR-1792 (1996) 